Article

\title{
People, Place, and Politics: Local Factors Shaping Middle-Class Practices in Mixed-Class German Neighbourhoods
}

\author{
Heike Hanhörster ${ }^{1}$, Isabel Ramos Lobato ${ }^{2, *}$ and Sabine Weck ${ }^{1}$ \\ ${ }^{1}$ ILS-Research Institute for Regional and Urban Development, Germany; \\ E-Mails: heike.hanhoerster@ils-forschung.de (H.H.), sabine.weck@ils-forschung.de (S.W.) \\ 2 Helsinki Institute of Urban and Regional Studies, Department of Geosciences and Geography, University of Helsinki, \\ Finland; E-Mail: isabel.ramoslobato@helsinki.fi \\ * Corresponding author
}

Submitted: 6 May 2021 | Accepted: 9 September 2021 | Published: 15 December 2021

\begin{abstract}
This article takes a nuanced look at the role played by neighbourhood characteristics and local policies in facilitating or limiting the ways in which diversity-oriented middle-class families interact and deal with people of lower social classes in mixed-class inner-city neighbourhoods. The study draws on interviews and social network analysis conducted in neighbourhoods with different socio-economic characteristics in the German cities of Hanover and Dusseldorf. A comparative view allows us to analyse how neighbourhood characteristics and local policies influence middle-classes' interactions across social boundaries. Our aim is to contribute to ongoing debates on urban policy options: In discussing the conditions encouraging cross-boundary interactions of specific middle-class fractions, we argue that the scope of local-level action is not fully recognized in either policy or academic debates.
\end{abstract}

\section{Keywords}

middle-class families; mixed-class neighbourhoods; network analysis; social boundary-crossing; social interactions

\section{Issue}

This article is part of the issue "In Good Company? Personal Relationships, Network Embeddedness, and Social Inclusion" edited by Miranda J. Lubbers (Autonomous University of Barcelona, Spain).

(C) 2021 by the authors; licensee Cogitatio (Lisbon, Portugal). This article is licensed under a Creative Commons Attribution 4.0 International License (CC BY).

\section{Introduction}

Much has been written in previous years about middleclass (dis)affiliation practices in mixed-class environments (Bridge et al., 2012; Vincent et al., 2004). While there is overwhelming evidence of such boundarydrawing and disaffiliation practices-spatially, socially, and symbolically-our study explicitly aims to identify specific local factors, such as neighbourhood characteristics and/or local policies, able to influence middle-class interactions across social boundaries. We thus argue in favour of a more detailed analysis of the drivers and dilemmas of those middle-class fractions who act against the grain (Reay et al., 2007) and reveal diverse social networks and inclusionary daily practices-at least to some degree.
At a time when the main discourse is on universal, structural forces of gentrification (Lees et al., 2016), there seems to be little room for manoeuvre to promote mixed-class neighbourhoods. However, our analysis aims to examine the sphere of influence local politics, including housing, school, and urban development still have on neighbourhood diversity and individual neighbourhood practices and routines. Our research is guided by the following questions: How do respondents' valuation of diversity translates into living with diversity and into boundary-crossing practices? How are these practices influenced and shaped by place (here understood as settings for social interrelations) and local politics?

By adopting an individual perspective, we illustrate the ways in which more diversity-oriented middle-class fractions interact with people of lower social classes. 
A comparative research design based on interview data collected in three inner-city neighbourhoods with different socio-economic characteristics in the German cities of Dusseldorf and Hanover allows us to reflect upon neighbourhood-specific factors and local policies enabling (or hindering) inclusionary/exclusionary practices. We deliberately selected households whose daily activities are generally oriented towards their immediate surroundings: middle-class families with small children whose family responsibilities and routine activities entail a close relationship with their neighbourhood (Goodsell, 2013 , p. 848). Our focus is on a specific middle-class subset: diversity-seeking middle-class families (Hanhörster $\&$ Weck, 2020). We are interested both in individual attitudes and practices regarding social diversity and neighbourly interaction, and in place-specific (neighbourhood) factors and local policies influencing and mediating middle-class practices. Identifying the factors allowing this particular middle-class fraction to act in greater accordance with their integration values could help support more integrative and diverse neighbourhoods.

\section{Cross-Class Boundaries: Evidence of Middle-Class Interaction in Housing, Public Space, and Education}

The question of middle-class formation and reproduction processes in socially diverse neighbourhoods has been widely investigated. These processes are intrinsically interlinked with the "boundary work" of middle classes towards their lower social class neighbours (Atkinson, 2006; Bridge et al., 2012; Butler \& Robson, 2003; Ley, 1996; Watt, 2009). The disaffiliation of middleclass households in socially diverse neighbourhoods becomes obvious in their selective use of neighbourhood infrastructures, a withdrawal into socially homogeneous residential enclaves, or symbolic processes dissociating them from households of lower social classes. Described by Atkinson (2006), this "colonisation" of neighbourhoods is expressed, for example, in a withdrawal into (more or less physically) gated communities. Such withdrawal can be a challenge when implementing the urban planning principle of achieving the right social mix, guided by the aim of creating and maintaining socially stable occupancy structures. This principle has gained relevance in Germany and includes strategies to create inclusive spaces to foster cross-class interactions in diverse neighbourhoods (Atkinson, 2006, p. 831; Hoekstra \& Pinkster, 2019).

Acknowledging the empirical evidence on middleclass boundary-drawing practices-also witnessed in our study-we deliberately adopt a different perspective in this article, building on literature looking specifically at cross-class alliances in mixed-class neighbourhoods, and looking for factors possibly supporting encounters and relationships across social boundaries in urban neighbourhoods. Going against the tendency to avoid people of lower social classes in the broader context of middleclass positioning and reproduction, the formation of such cross-class alliances has occasionally been reported in studies (Brown-Saracino, 2009; Lawson et al., 2016). For the social fields under study here-housing, public space, and education - there is a certain amount of evidence on the conditions needed for establishing contacts and interaction across social boundaries. For instance, spatial and social opportunities such as public events and repetitive routine contacts are among the factors forging links between different groups and people (Amin, 2002; Wilson, 2014). Even in the field of education, reportedly of key importance for middle-class reproduction (Butler \& Robson, 2003, p. 144), some middle-class parents deliberately send their children to local, socially diverse schools (Byrne, 2006; van Zanten, 2013; Vincent et al., 2004), emphasising the "real world" experience and benefits of mixed-class schooling for their own children, such as intellectual and cultural enrichment (Raveaud \& van Zanten, 2007). However, even those parents embracing diversity in other social fields may perceive it as a threat when it comes to their children's education (Boterman, 2012), often facing the dilemma of having to decide between being a "good citizen," i.e., striving for equal educational opportunities, and being a "good parent," i.e., giving priority to their own child's future position (Frank \& Weck, 2018; Raveaud \& van Zanten, 2007).

As argued in several papers, families might take a moral stand and deliberately seek to preserve a place's social diversity and authenticity (Brown-Saracino, 2009; Hanhörster \& Weck, 2020). While scholarly literature tends to see these practices as individual choices and exceptions to the rule, the question has rarely been discussed as to how far local policies (broadly defined here as formal and informal political actions or practices of local governance) have an influence on individual and collective (place-specific) practices. We hypothesise that middle-class mixing and control are contingent upon the close interplay between households' individual strategies, neighbourhood characteristics, and local policies shaping cross-class social interactions.

Considering the above-mentioned studies and our own empirical findings, we argue that not all middleclass parents avoid social diversity or feel comfortable with the marginalization of lower classes in upgrading neighbourhoods. Although such parents are certainly not a majority in the neighbourhoods studied, they are a critical fraction in terms of the social outcomes of local policies facilitating cross-class interactions. While in the current academic discourse the focus is mainly on structural and universal factors explaining gentrification, displacement and middle-class homogeneity across places (Lees et al., 2016), we additionally want to draw attention to the scope for action and the local factors shaping cross-boundary interactions. Except for the notable studies of Butler and Robson (2003), Boterman (2012), and Andreotti et al. (2013), few contributions trace middleclass practices across different fields and neighbourhoods. This article aims to reveal how individual preferences and values, as well as place and policies, influence 
social practices in dealing with difference, putting a focus on both narratives and practices from different social fields.

\section{Research Design}

The research findings stem from a five-year-research project (2013-2017) looking at mixed-class inner-city neighbourhoods in Dusseldorf and Hanover. The two chosen cities are similar in terms of their status as federal state capitals; both are also university and trade fair cities. Compared to Hanover, Dusseldorf is better-placed in terms of economic development, is located in a wider metropolitan region, and has a tighter housing market. We chose these two cities for reasons of accessibility and based on local knowledge and statistical analysis, but also because they both represent "ordinary" German cities, in contrast to other, more prominently researched cities, such as Berlin, or hot market cities, such as Munich. The fieldwork started in Hanover, with the research in Dusseldorf explicitly used to reflect and contrast earlier findings in Hanover. More recent literature on growing gentrification occasioned us to review our empirical findings, systematically cross-analysing the factors influencing middle-class practices in our sample of socially diverse neighbourhoods.

Table 1 below shows the status of the cities and chosen neighbourhoods at the end of our empirical research. Since then, housing prices and pressure on inner-city areas have continued to rise in both cities, as in most big cities in Germany. Current developments, e.g., the upgrading of infrastructures, are embedded in a different political climate at both city and neighbourhood level. While in Hanover gentrification processes are critically observed and discussed in neighbourhood committees, the local tenants' association, political bodies, and the media, this is much less the case in Dusseldorf, a city tending to pursue neo-liberal policy goals. For example, urban politics' influence on the regulation of the rental housing market (e.g., through "milieu protection regulations" [Milieuschutzsatzung]) was neglected until 2019 (Zimmer-Hegmann, 2020).

\subsection{The Researched Neighbourhoods}

We chose the neighbourhoods based on neighbourhood statistics and local insights. They are similar as regards their (inner-city) location, being former regeneration areas and publicly debated as being subject to gentrification. At the same time, we deliberately looked for contrasts to investigate how middle-class strategies and practices differ from one neighbourhood to the other. Whereas the Hanover neighbourhood, where we started the empirical data collection, is close to the city average in terms of unemployment and persons receiving welfare benefits, we chose the neighbourhoods in Dusseldorf deliberately to widen our sample and the range of neighbourhood characteristics. While the Dusseldorf innercity neighbourhood Northville (all neighbourhoods in this article are pseudonymised) has recently seen a high influx of middle classes, the two adjoining neighbourhoods (Southville and Highsprings) have experienced only selective middle-class in-migration.

Located in the inner city of Hanover, Limeton is composed of two wards (North Limeton and South Limeton). As they have similar characteristics, they are considered as one neighbourhood. Close to the University of Hanover, Limeton is a vibrant area with a socially and ethnically heterogeneous population. In the 1980s, it gained a reputation as home to left-alternative groups, especially from the punk scene. Over the last years, it has experienced an influx of middle-class households, steadily pushing up rents and property prices and engendering a strong local discourse on gentrification. According to neighbourhood statistics, the percentage of inhabitants receiving social security benefits and the share of non-German residents have decreased over the last years.

Table 1. Key figures on the cities and the researched neighbourhoods at the time of our empirical research (2017).

\begin{tabular}{lcc}
\hline & Dusseldorf & Hanover \\
\hline Total population & 639,407 & 541,773 \\
Unemployed/persons receiving & $8.6 / 12.3$ & $6.8 / 15.6$ \\
welfare benefits (in \%) & & North Limeton: 17,829 \\
Research neighbourhoods: total & Northville: 24,617 & $7.4 / 16.9$ \\
population (absolute numbers)/ & $9.9 / 13.8$ & \& \\
unemployed (in \%)/persons receiving & Southville: 10,319 & South Limeton: 16,619 \\
social welfare benefits (in \%) & $14.6 / 23.3$ & $7.7 / 18.4$ \\
& $\&$ & Highsprings: 30,391 \\
\end{tabular}

Source: Landeshauptstadt Düsseldorf (2020) and Landeshauptstadt Hannover (2018, 2021). Note: The data is comparable within the cities, but not strictly between the cities. 
Northville, Dusseldorf, has a high share of recently renovated, late 19th-century buildings and inviting streets full of corner stores, art galleries, and cafés. Housing prices have shot up over the last years, and even affluent middle-class families can now hardly afford to rent or buy adequate housing. Northville represents the most gentrified and least socially diverse neighbourhood type in our sample, with just few working-class or poor inhabitants left.

Southville and Highsprings, Dusseldorf, are located adjacent to Northville but are neighbourhoods with very selective signs of upgrading and a relatively small influx of middle-class households. Both neighbourhoods are considerably more diverse in terms of social and ethnic composition (see Table 1). We selected them as "contrasting" neighbourhoods, with comparably high indicators of socio-economic disadvantage. In the following, Southville and Highsprings are discussed as a single neighbourhood, not only because they have common features but also because the identified group of diversity-seeking middle-class households (compared to disaffiliating middle-class households) is too small in these neighbourhoods to discuss them separately. Indeed, this constitutes a first finding with regard to differences between the three case study neighbourhoods.

\subsection{Methodology}

Our research findings are based on semi-structured interviews with 59 middle-class households, 28 in Dusseldorf and 31 in Hanover. Our sampling strategy for identifying respondents used various approaches: We contacted childcare centres and child-related institutions (associations, music schools), used personal contacts, and regularly visited neighbourhood playgrounds and talked to parents in situ (the most fruitful approach). In addition to household interviews and expert discussions, we included a participatory observation documenting encounters in different public spaces for several months. All respondents had children of primary school age and below and were defined by us as "middle class," mainly based on educational qualifications and occupational data, i.e., using higher professional/university education as the threshold for speaking of middle class (Blokland \& van Eijk, 2012; Ley, 1996). Due to changing occupations, labour market and income distribution, defining class has become increasingly difficult (Devine et al., 2005).
Class is often defined in terms of occupation or income. Due to data availability, the definition for our article is based solely on parents' educational attainment and their occupation. However, since class is becoming more cultural (Bennett et al., 2009), defining parents' social status solely by their educational attainment and occupation might be a good approximation (Blokland \& van Eijk, 2012) -in particular in Germany, where both play a crucial role for social positioning.

Characterising the overall sample of 59 , and in line with the cities' different economic profiles, more respondents in Dusseldorf worked in senior business positions (engineer, product manager, architect, project manager, IT professional, doctors). By contrast, more respondents in Hanover worked in social professions, i.e., social workers or youth workers, or were on parental leave. These differences reflect neighbourhood sorting, with the specific neighbourhood history and social climate in Hanover attracting persons with higher cultural capital. Table 2 below provides insights into the profile of the overall sample.

The interviews were semi-structured. We looked for empirical evidence of boundary-making and -crossing at three different levels: respondents' social (egocentric) networks, usage of neighbourhood facilities and settings (from kindergarten/schools to leisure activities), and storytelling about the neighbourhood. Name generator questions helped to qualify the respondents' social (egocentric) networks. The generator included different questions to explore forms of emotional and functional support given by the respondents, ranging from with whom they would talk about personal issues to questions aimed at identifying more instrumental forms of support through, for instance, lending tools or looking after children. We also collected information on respondents' usage of (child-related) infrastructures and activities in a standardized way (what places or infrastructure they used, how frequently, and whether these were located within or outside the neighbourhood). Moreover, the interview guidelines contained qualitative open questions about perceived neighbourhood characteristics or plans to move out of the neighbourhood. Combining data from the open qualitative parts of the interview with the standardized data on respondents' spatial activity patterns and social networks allowed us to distinguish between and confront respondents' narratives with their actual practices. The interviews were carried out from

Table 2. Characteristics of interviewees: Overall sample.

\begin{tabular}{lrrr}
\hline Overall sample & Dusseldorf & Hanover & Total \\
\hline Total number of interviews & 28 & 31 & 59 \\
Female/Male & $22 / 6$ & $22 / 9$ & $44 / 15$ \\
Ownership/Renting & $7 / 20^{*}$ & $7 / 24$ & $14 / 44$ \\
Migration background/none & $8 / 20$ & $6 / 25$ & $14 / 45$ \\
Years of residence: $1-3 / 4-10 / 11+$ & $8 / 15 / 5$ & $8 / 14 / 9$ & $16 / 29 / 14$ \\
\hline
\end{tabular}

Note: * (1 unknown). 
spring 2013 to spring 2014 in Hanover and from spring 2015 to spring 2016 in Dusseldorf. All interviews were conducted in German using the same interview guidelines. All were recorded and fully transcribed. The software MaxQDA was used for in-depth text analyses.

Adopting a non-ethnic approach (Wimmer, 2008, p. 71), we focus exclusively on the class dimension (see above) when referring to mixed neighbourhood contacts. According to our network analysis, nearly half of all respondents had no inter-class contacts at all in their neighbourhood. Such a contact is - to give an examplebetween a person with a university degree and one with secondary education as their highest educational qualification (excluding family members). Eleven respondents had several (two or more) such contacts, while the rest had only one.

\subsection{Specific Interviewees}

For this article, we carefully selected three interviewees from the overall sample to illustrate what we found to be typical for the practices, arrangements, and arguments of the wider boundary-crossing middle-class fraction in the specific neighbourhood. All three were diversityseeking in their narratives, though this only partly translated into inter-class neighbourhood networks and the usage of mixed spaces. Our focus on these three protagonists allowed us to track their routines and interactions across the different social fields (housing, public space, and education). The three had features in common, such as renting their apartments, being parents of children below school age, and living in dual-earner partnerships.

Sara (female, migration background, two children, self-employed) had known Limeton, where she lived with her partner, their new-born baby, and their three-yearold child, for about 20 years at the time of our interview. Originally moving to Hanover to study, she is representative of many others in Limeton, feeling a very strong sense of belonging and not contemplating living anywhere else in Hanover, especially not in a more peripheral or gentrified neighbourhood. After finishing her studies and living abroad, she returned to Hanover in 2006. She enjoyed the neighbourhood's vibrancy and its amenities, but also its familiarity and living close to people she knew. Of her 10 network contacts, seven were located in her neighbourhood, while three local contacts had lower educational qualifications. She had supported two of them in finding a good kindergarten, new job or flat, and helped one of them with emotional support.

Jan (male, no migration background, one four-yearold child, public sector employee) had been living for seven years with his partner in Northville at the time of our interview, having moved there before the recent "neighbourhood hype." Attached to Northville, he specifically valued the aesthetic layout and design of the streets and houses. While critical of the ongoing gentrification, he was aware of the benefits linked to the upgrading, such as the variety of cultural activities, cafés, restau- rants, which he used frequently. Jan was ambivalent about living in a gentrified neighbourhood, but for the moment stayed put in a "safe" position, benefiting from a moderate rent as a long-term tenant. Of his ten network contacts, four were located in his neighbourhood. One of them had lower educational qualifications, with the regular interaction linked to mutual child-related (care) activities.

Leila (female, migration background, one four-yearold child, socio-cultural sector) was born and raised in a neighbouring inner-city area in Dusseldorf, had left to study and moved back three years ago at the time of our interview. Moving to Highsprings with her partner was a decision based on the relatively low level of rents and proximity to the main station. Though clearly open to diversity and herself working in projects promoting disadvantaged children, the daily encounters with disadvantage were sometimes "a bit too much" for her. In her local spatial activities and networks, she was more selective than Sara and Jan. Of her 19 network contacts, three were located in the neighbourhood, all people with degrees like herself. Her overall network was however socially diverse, featuring contacts to less-educated people, most of whom she had known for a long time, through family or her own childhood, and with whom she regularly interacted and supported both emotionally and instrumentally.

It should be noted that, even though two of these interviewees had a migration background, they had been socialised in Germany. Moreover, they were not identifiable as migrants on account of their physical presence (skin colour, wearing a headscarf) and language.

In the following sections, we analyse the three respondents' narratives on housing, public space, and education, illustrating how their valuation of diversity translates into living with diversity and boundarycrossing practices, and how these practices are influenced and shaped by place and local policies.

\section{Neighbourhood Choice and Housing: Searching for a Diverse Neighbourhood and Actively Practiced Neighbourhood Life}

All three interviewees sought an affordable "middle" middle-class residential location, yet near to places of everyday life. Our interviewees' narratives showed that neighbourhood diversity was expected to be part of an actively practiced neighbourhood life instead of just "social wallpaper" (Butler, 2003), as evidenced by numerous quotes showing that most of the contacts in their immediate surroundings went well beyond a cursory staircase "hello."

Like many other interviewees in Limeton, the sample neighbourhood most characterised by a left-wing alternative milieu, Sara spent most of her leisure time in the neighbourhood. She loved the togetherness of different social groups and the feeling of public familiarity engendered by regularly re-encountering acquaintances 
and friends on the streets. In her narratives, Sara clearly distanced herself from the upper middle class, appreciating the neighbourhood for not (yet) being gripped by gentrification: "There are no people with a pretentious lifestyle living here.....It [remains] a left... an alternative neighbourhood." Like many other interviewees in Limeton, Sara had a clear picture of the neighbourhood's authenticity which she wanted to see maintained (Brown-Saracino, 2009). The close living-together of different social groups is embedded in and encouraged by city politics, with the Hanover city administration providing various niches for mixed-class subsets such as housing projects and controlled upgrading as well as social housing developments, and even tolerating alternative housing forms such as squatted houses. Neighbourhood redevelopment in the past years has been carried out by the public administration and a non-profit, city-owned building company, with the aim of keeping rents at a reasonable level, allowing people to stay in the neighbourhood after redevelopment and maintaining the local inhabitant structure through co-operative, communityoriented housing companies. Despite some conflicts with her immediate neighbours (about noise or garbage), Sara loved the neighbourhood's overall social climate and would not consider moving away. This finding was in line with the "ethos of mixing" described by Wessendorf (2014, p. 103), an expectation of mutual co-existence and an "implicit grammar of living in a super-diverse area."

By contrast, developments in both case study neighbourhoods in Dusseldorf were much more influenced by profit-oriented players. Jan, our interviewee in Northville, the most gentrified neighbourhood in our sample, had moved into his rented apartment before gentrification and the accompanying significant increase in rents. He criticised the influx of upper-middle-class residents with a more consumption-oriented lifestyle and the changing business infrastructure: "Something noticeable is the obvious influx of higher socioeconomic groups... and the corresponding boutiques and hairdressers. The process began to intensify in $2008 \ldots$ such a process of displacement....Northville has basically evolved into a "hype neighbourhood.'" This quote demonstrates Jan's ambivalent feelings towards a process of neighbourhood change, with the infrastructure becoming more orientated towards the (upper) middleclass. This did not encourage Jan to remain in Northville, instead evoking feelings of alienation. Obviously, diversity seekers like Jan are in search of that fine balance between neither living in an overly disadvantaged neighbourhood nor in a too posh and fancy one. He would have appreciated more interaction with socially diverse groups. The main reason for staying put was the comparably low rent and living conditions that would be hard to find elsewhere in Dusseldorf's tight housing market.

While both Sara's and Jan's narratives of symbolic boundary-drawing were primarily directed towards drawing boundaries vis-à-vis the upper middle classes, the interviewee in Highsprings, the most diverse and least gentrified neighbourhood in our sample, highlighted various aspects. Leila had chosen her residential location not primarily based on neighbourhood characteristics, but on the lower level of rents and the location close to the main station. Like the other interviewees, Leila emphasised that she appreciated an ethnically and socially mixed living environment. However, the neighbourhood offered hardly any facilities oriented towards the middle classes and their conscious wish for a green consumption infrastructure such as organic shops or cafés. Leila's locational choice was thus ambiguous: "We moved here, actually with some... heartache, because the neighbourhood is quite different....I would put it that way: We have come to terms with it." This quote seems to refer to what Watt (2009) and Pinkster (2013) describe as narratives of "good value for money." However, different to the findings of these scholars, our interviewees showed no indifference towards the neighbourhood. Instead, Leila's narratives illustrated her ambivalence, torn between her strong appreciation of diversity and the question of how much contact with socially disadvantaged groups she could tolerate in her daily life:

I believe that you just need to find the right balance... somehow you think: [Let's get] out of the academic enclave! Out of the Latte Macchiato-YogaMontessori world!'... In this neighbourhood, I always have the dilemma... this decision for my personal life: 'Do I want to have this in my everyday life?'

At the same time, it became clear that Leila's position and status as one of the few "middle-class pioneers" in the neighbourhood had a special charm for her. She wanted to make a change by actively participating in local neighbourhood life.

Unlike our interviewees in Limeton and Northville, Leila was not yet sure about whether to stay put or to leave the neighbourhood. Like all our other interviewees in Highsprings, her decision to stay put was dependent on whether other young middle-class families remained and on whether she was successful in finding a housing "niche" giving her a feeling of being at home and offering a secure environment for her children. Leila expressed her wish to have more intense social interactions in her immediate surroundings: "Sure, I would like to live somewhere with... more 'docking stations,' something more than just anonymous rent payments." The quote illustrates the wish for more fine-grained forms of affiliation. In neighbourhoods with a significant share of inhabitants with a lower social status like Highsprings, such "docking stations" - focal points drawing people with the same lifestyle together - can strengthen middle-class families' feeling of local belonging and facilitate actively practiced neighbourhood life (Karsten, 2014).

Interviewees from Highsprings pointed out the positive effects of middle-class households' small-scale concentration in some housing blocks or buildings. However, 
this finding should not be understood as a plea for middle-class-focused housing developments or gated communities. Rather, the research underlines the need to concentrate efforts on creating public or semi-public spaces open to and attractive for different social groups, and stimulating their active use.

Looking at previous research, it was not surprising that Leila, our respondent from a quite homogeneous low-income neighbourhood, was most ambivalent in her narratives and practices. Discontent was also expressed by Jan, our respondent in Northville, the most gentrified neighbourhood, with the continuing influx of upper-middle-class residents and the loss of social diversity evoking feelings of alienation, a process also described by Jackson and Butler (2015). He longed for a socially more diverse, "ordinary" neighbourhood, distancing himself from middle-class fractions not "doing diversity" but rather consuming it as part of their yuppie lifestyle (Jackson \& Butler, 2015, p. 2362). In this respect, the case of Hanover-Limeton is interesting since, in contrast to Dusseldorf, local housing policies have had a positive influence on the fact that groups with different social backgrounds feel locally rooted in the neighbourhood.

\section{Encountering Diversity in Public Spaces}

Our three protagonists valued neighbourhood encounters with friends, acquaintances, or strangers in public or semi-public spaces such as parks, playgrounds, libraries, shops or cafés. However, the selected neighbourhoods offered very different opportunities for such interaction.

Interviewees in the Hanover-Limeton neighbourhood were very rooted in their neighbourhood, as witnessed by Sara whose activities and social networks were almost exclusively located in the neighbourhood. The public spaces she viewed as relevant for herself were the same as those mentioned by the other Limeton interviewees. This in turn led to high rates of re-encountering other (middle-class) residents as well as to a feeling of security about what to expect from certain spaces (described as public familiarity by Blokland \& Nast, 2014).

Two kinds of public spaces were highlighted in Sara's narrative. First, she described the main shopping street as a space she liked, and which met her needs: a vibrant street full of shops, eateries, and cafés with different price levels. This diversity drew different social groups to the street, allowing people "to rub shoulders" (van Eijk, 2010). Settings such as the ice-cream parlour or the drugstore seemed to create a basis for "meaningful contact... a respect for difference [that] can be produced from particular kinds of purposeful, organized micro-public encounters" (Valentine, 2008, p. 334). The second place was the church square located just a short distance away from the main shopping street. For her, the square functioned as an opportunity for casual encounters or for meeting up with her friends in the cafés and restaurants: "[It has] an almost Italian atmosphere... and it is nice with the kids, you walk by, and you meet people."
This quote well reflected the much-appreciated effortlessness of combining functional and social activities.

Narratives of diversity in public spaces were much more positive in Hanover than in Dusseldorf. We attribute this to the balance of mixed and segregated spaces and neighbourhood spaces frequented by all neighbourhood groups. In addition, the long-term political climate of tolerance towards subcultures might have contributed to inhabitants learning to deal with "otherness," with the Hanover city administration providing space for alternative housing co-operatives and civic initiatives. This public example of tolerance and acceptance of diverse lifestyles within the neighbourhood has now become part of the neighbourhood's (self-)image, determining the ways people use their neighbourhood.

A different relationship to public spaces and infrastructures can be found in the more gentrified Northville in Dusseldorf. With the overall development in Dusseldorf much more influenced by profit-oriented players, our interviewees' evaluation was more ambiguous, as witnessed by Jan in relation to the pub, café, and restaurant infrastructure. On the one hand, he appreciated the new facilities-such as healthy restaurantsestablished as a reaction to the influx of higher income groups. On the other hand, he was not as embedded in the neighbourhood as his Hanover counterparts and actively sought socially mixed spaces outside it. While Sara stressed that she saw "no need to go to the city centre or to other neighbourhoods," Jan perceived his neighbourhood as too gentrified, leading to him looking elsewhere: "I just consider it very interesting, I like to walk along there-the train station atmosphere around that square and also all those Turkish and Arabian stores. I find it really attractive." He also selectively frequented more mixed settings in adjoining neighbourhoods generally known for their higher tenant turnover and low-income groups. This strategy contrasted with the bridging-out strategies to better-off places primarily described in the literature (e.g., Butler \& Robson, 2003; Pinkster, 2016).

Living in Dusseldorf Highsprings, Leila saw the public spaces, streets, and squares as providing few opportunities for the interactions appreciated by her. She constantly felt that her family's way of life did not resonate with the neighbourhood, with her and her family personifying the "others," as exemplified by narratives of critical situations at neighbourhood playgrounds:

And then I sometimes become aware, especially with a small child, of situations in the playground where kids are being hit or kicked or screamed at and none of the other parents seem to care. I think 'That's an atmosphere that is going to depress me in the long run.' I just don't know whether we will carry on living here.

In contrast to Jan's positive perception of Turkish and Arabian shops (in a neighbourhood he did not live in), 
Leila felt out of place in Highsprings, being the only one not speaking Arabic in certain streets and shops. When visiting public settings, she preferred to do so in groups of people she knew beforehand. The only spaces where she perceived interactions with previously unknown people as being positive were embedded in a larger network of settings, with the kindergarten at the centre. The network consisted of groups of people with common values, e.g., belonging to a neighbourhood club connected to a shop for organic produce, an urban gardening project or a neighbourhood café. Such selective belonging draws symbolic boundaries around middle-class enclaves, as described by Atkinson (2006).

Bridging-out is a strategy used by Leila to cope with neighbourhood aspects she does not feel comfortable with: "I don't do much in the neighbourhood [in my free time]. There is simply no place... where you can just hang around as a young family... that combination of cafe and playground, it's just not there." However, Leila did not perceive homeless people or junkies in public spaces primarily as a threat or nuisance, stating that these challenging encounters were also important as a learning experience for her child, "a city kid growing up between organic shops and syringes and whatnot." A positive example of casual interaction for Leila was a family-run bakery chain store which gave her a feeling of community she otherwise missed. The repetitive contacts in this setting enabled class- and ethnicity-bridging interactions as described by Wilson (2014), providing a daily, effortless combination of functional and social purposes: "What I find immensely charming, what has been a glimpse of hope for me, is the bakery at the corner... run by a really nice Greek family... with whom we have developed a kind of village-like relationship." Leila spoke of the important emotional support she received from the bakery's non-middle-class staff, referring for example to how the family "had been with her" during her two pregnancies.

In this respect, our findings resonate with other studies: The more the middle-class subset perceives itself as a minority in the neighbourhood, the more selective belonging becomes apparent. Thus, the previously mentioned niches or "docking stations" in the neighbourhood can generate comfortable and predictable social interactions, thereby strengthening feelings of local belonging and familiarity and making it easier to accept and endure negative encounters with diversity. Leila's wish for anchor points in the neighbourhood which she can actively shape does not go along with a deliberate strategy of distinction from people of lower social classes.

\section{Diversity and Education: Similar Aspirations, But Neighbourhood-Specific Practices}

Parents in all three neighbourhoods appreciated the diversity in education. However, as already illustrated by previous studies on middle-class parents' choice of school (Boterman, 2012), it was also more often perceived as a threat than in other social fields.
In contrast to their choice of housing and the use of public space, diversity in education was in general a more sensitive topic for all our interviewees. However, we were able to clearly identify neighbourhood-specific practices linked strongly to local/regional policies. Facilitated by liberal local policies sheltering their founders from red tape, Hanover has a comparatively high number of parent initiatives, making the deliberate choice of childcare centres based on ideological and lifestyle considerations easier-and thereby enabling middle-class parents to stay in Hanover's diverse innercity neighbourhoods. For her choice of childcare, Sara thus focused on the quality of care, as measured by a good staff-children ratio and a shared understanding of parenting practices and education between parents and staff. Giving her participation and decision-making rights, private childcare centres set up at the initiative of parents and run by them were the right choice for her. The homogenous middle-class composition seemed not to be the primary reason for her choice; it was rather a logical consequence of the required commitment and similarities in lifestyles and parenting. Like other parents in Limeton, ideological and lifestyle considerations such as organic nutrition determined choices more than a deliberate strategy of distinction-albeit with the (unintended) result of distinct networks.

This was completely different in Dusseldorf. While childcare costs are means-tested in most German cities, meaning that there is little difference between public and private childcare facilities for high-income groups, public childcare centres in Dusseldorf are free. As a result, even high-income parents give them precedence. Theoretically, this should lead to a higher level of diversity in public childcare. De facto, however, this instead intensifies careful selection and parental rumours about childcare centres and their composition. The scarcity of public childcare places in combination with the non-transparent admission process not only creates uncertainties but also generates middle-class advantages in choosing and accessing certain childcare centres-even though these parents frequently present their admission as the luck of the draw.

Jan clearly appreciated the social and religious mix in the childcare centre his daughter attends:

I really like it a lot [the diverse composition]....And all the other religions here; it's great that she can see that there are other groups, other people, who live differently to us. Nevertheless, it is obvious that these differences sometimes lead to different groups even in our childcare centre. And the kindergarten teachers put a lot of effort into thinking about how to bring everyone together, again and again. I think that is really good.

The quote illustrates clearly that successful social mixing-whether in childcare or different social settings-requires a certain level of mediation and 
intervention. Jan was aware of the higher level of negotiation needed to deal with the childcare centre's diverse composition, but was nevertheless satisfied, clearly contrasting the centre to the parent initiative close by where "there are only people like us." Although he seemed somewhat uncertain as to whether the quality of care in other, more homogenous childcare centres was higher, he stressed his luck to have obtained a place in a public childcare centre. Living in the least socially mixed neighbourhood in our sample facilitated his acceptance and reduced his concerns about his daughter attending a more diverse childcare centre.

Living in a far more socially mixed neighbourhood, the presence of interested and committed middle-class parents was Leila's chief concern when searching for childcare. She managed to get a place in her first-choice centre, an "incredibly homogenous" middle-class parent initiative which she deliberately chose over the neighbouring centres attended by children of a "less interested" clientele. Like Sara, Leila valued similar notions of education and lifestyle among parents and staff and attached importance to co-determining the centre's daily routines. In her case, however, the search for such similarities was closely interlinked with her own social life and her attempts to build up a local social network in Highsprings:

I appreciated the idea of a parent initiative since it brings you into closer contact with the other parents. And I thought it nice to see who else was living here and how we could put down more roots in this neighbourhood.

With the aim of building up relationships with "people like us" in a quite diverse neighbourhood, the choice of the "right" childcare centre was more important for her than for Sara and Jan.

Local/regional policies in combination with placespecific factors also play a significant role in explaining parents' choice of primary schools. Most interviewees in Limeton seemed to generally accept and appreciate the local schools. This could be determined by the education system where primary school catchment areas exist (Noreisch, 2007). Sara's quite exceptional choice of a primary school outside the neighbourhood was based solely on the chosen school's offer of Polish lessons-one of the very few signs of an intersection between our interviewees' social and ethnic background.

By contrast, in the federal state of NRW where Dusseldorf is located, primary school catchment areas have been abolished. Consequently, choosing a primary school other than the local one is comparatively less queried than in Hanover. Interestingly, many respondents in Northville nevertheless chose a local school. Strategies of avoiding schools with the "wrong" social and ethnic composition were not mentioned as being relevant for Jan's choice, with him instead focusing on spatial proximity and the quality of schooling offered. However, when asked directly, Jan self-critically expressed his doubts about whether his choice criteria would still be relevant if he lived in a more diverse neighbourhood with more diverse primary schools:

I live in Northville, and there are two schools in my immediate vicinity, both of which have a good reputation. I guess, I just do not have to be concerned so much with that [a school's composition]... as I would have to be if I lived in Highsprings or Southville, where the next primary school is a very different one.

Aware of the segregating role middle-class school choice strategies have, Jan was therefore glad that the comparatively homogenous schools in his neighbourhood allowed him to be less concerned with a school's composition and more with other criteria-even though education policies allowed bridging-out strategies to be pursued.

By contrast, this was something that Leila could not "afford." Nevertheless, she did not categorically rule out the neighbourhood's primary schools, emphasising that she was "really looking for social mix. I do not search for a homogenous structure at all." Despite knowing about the neighbourhood schools' poor reputation among parents, she deliberately gathered her own information, talked with teachers, and clearly questioned the segregating effects of her own school choice:

I do not want to create homogenous structures, but it is hard to create the kind of heterogeneity I want. And that's exactly the moment when you ask yourself: 'Do I really want to be one of the first who sends her child to this school in order to create a higher level of mix, or should I instead play safe?'

However, the social ideal of a socially and ethnically mixed school collided with the wish to give one's own child a good start in life (a dilemma also described in Raveaud \& van Zanten, 2007) when it came to Leila, living in the most diverse neighbourhood in our sample. She doubted whether the latter was possible in a school where a high proportion of children not speaking German properly might command teachers' full attention. Her concerns seem to be justified: in reaction to free school choice, several primary schools have started developing specific profiles. In neighbourhoods like Highsprings, this has resulted in a focus on promoting German language skills, which, as reflected by Leila's concerns, in turn encourages (German) middle-class parents to choose a school outside the neighbourhood (see Ramos Lobato, 2017; Ramos Lobato \& Groos, 2019)-a practice even encouraged by local school staff:

On the one hand, I think 'great school, good teachers, and they need people like us to send their children there so that things change.'... But then you remind yourself that your child will be prepared for 
secondary school there and the teacher tells you in no uncertain terms: 'To be honest, the problems we have here have nothing to do with preparing children for secondary school.'

As we know from previous research (Jennings, 2010; Noreisch, 2007), acting as a professional in a meritocratic education system and feeling encouraged to "protect the educational careers of the brightest students" (van Zanten, 2013, p. 93), some teachers even discouraged middle-class parents from choosing schools in Highsprings.

The abolition of primary school catchment areas in Dusseldorf thus facilitates bridging-out strategies, thereby further strengthening distinct middle-class networks. However, whether parents make use of free choice depends on specific local factors, such as the neighbourhood itself.

\section{Conclusions}

The aim of our research in two German cities was to analyse the inclusionary/exclusionary daily practices of a specific fraction of middle-class households in their interrelation with place-specific neighbourhood characteristics and policies. We argue that, in order to understand differences in middle-class practices and routines across neighbourhoods, the close interplay between households' individual strategies, neighbourhood characteristics, and local policies shaping inter-group social interactions needs to be considered.

In line with other research, we found evidence that middle-class households follow different strategies to fence themselves off from "undesirable others" in the fields of education, housing, and leisure time, but not consistently across all fields. However, even in neighbourhoods with comparably high levels of socio-economic disadvantage, a specific fraction of the middle class does not strive for social and spatial enclaves, instead seeking "docking stations," non-excluding spaces which help reduce anonymity and facilitate neighbourhood life.

The perceived necessity for social and spatial distinction is shaped not only by individual resources and preferences, but also by the degree to which middleclass households feel encouraged to actively shape and create local settings and whether they perceive themselves as active agents and part of local community life. We have shown that a specific fraction of the middle class perceives gentrification neighbourhoods, characterised by middle-class infrastructures, as dull and less stimulating. Taking Limeton/Hanover as an example, we were able to demonstrate the long-term influence of the local political culture on the social climate of tolerance and political support for local engagement. Meaningful contacts-which potentially facilitate resource transfers across different social groups-are embedded in a publicpolitical discourse in the neighbourhood and the city as a whole. The positive social climate, as perceived by all our interviewees, not only attracts further households with similar values, but also renders distinction strategies less necessary. In short: city and housing policies can ensure framework conditions helping inhabitants to handle diversity.

As expected, distinction strategies in the field of education are much more prominent than in the fields of housing or the use of public space. However, even educational choice is clearly shaped by federal state and city policies: The non-transparent allocation of childcare places in Dusseldorf minimizes household agency, creating clear advantages for alert middle-class households and in turn contributing to further educational segregation and less opportunities to "rub shoulders."

Drawing specifically on the example of Limeton, we argue that neighbourhoods do not necessarily follow a predefined path of gentrification, inevitably leading to less local solidarity. Relating observable differences in individual routines and practices to local factors helps us to identify the role and potential influence of local policies and the scope of action for city administrations. With their influence on local housing, neighbourhood and education policies, city administrations can modulate place-specific limits and opportunities for cross-class interaction. Importantly, successful social mixing in social settings such as childcare centres or the immediate housing environment requires a certain level of mediation and intervention. While it is essential to recognize the powerful structural forces shaping urban development in contemporary times, it is equally important not to lose sight of existing opportunities to intervene in neighbourhood change processes, paying greater attention to the influence of local policies.

\section{Acknowledgments}

We would like to thank the academic editor and the anonymous reviewers for their constructive comments and suggestions on an earlier version of this article. We are grateful to our former colleague Sabine Beißwenger, who has contributed to interviews and discussions this article is based on.

\section{Conflict of Interests}

The authors declare no conflict of interests.

\section{References}

Amin, A. (2002). Ethnicity and the multicultural city: Living with diversity. Environment and Planning A, 34(6), 959-980.

Andreotti, A., Le Galès, P., \& Fuentes, F. J. M. (2013). Controlling the urban fabric: The complex game of distance and proximity in European upper-middle-class residential strategies. International Journal of Urban and Regional Research, 37(2), 576-597.

Atkinson, R. (2006). Padding the bunker: Strategies of 
middle-class disaffiliation and colonisation in the city. Urban Studies, 43(4), 819-832.

Bennett, T., Savage, M., Silva Bortolaia, E., Warde, A., Gayo-Cal, M., \& Wright, D. (2009). Culture, class, distinction. Routledge.

Blokland, T., \& Nast, J. (2014). From public familiarity to comfort zone: The relevance of absent ties for belonging in Berlin's mixed neighbourhoods. International Journal of Urban and Regional Research, 38(4), 1142-1159.

Blokland, T., \& van Eijk, G. (2012). Mixture without mating: Partial gentrification in the case of Rotterdam, the Netherlands. In G. Bridge, T. Butler, \& L. Lees (Eds.), Mixed communities: Gentrification by stealth? (pp. 299-318). Policy Press.

Boterman, W. (2012). Residential practices of middle classes in the field of parenthood [Doctoral thesis, University of Amsterdam]. UvA-DARE (Digital Academic Repository). https://dare.uva.nl/search? identifier $=544 b 1 e 89-015 e-437 a-8 d 55-1608 c 41 d e b 3 d$

Bridge, G., Butler, T., \& Lees, L. (Eds.). (2012). Mixed communities: Gentrification by stealth? Policy Press.

Brown-Saracino, J. (2009). A neighborhood that never changes: Gentrification, social preservation, and the search for authenticity. University of Chicago Press.

Butler, T. (2003). Living in the bubble: Gentrification and its "others" in North London. Urban Studies, 40(13), 2469-2486.

Butler, T., \& Robson, G. (2003). London calling: The middle classes and the re-making of Inner London. Berg.

Byrne, B. (2006). In search of a "good mix": "Race," class, gender and practices of mothering. Sociology, 40(6), 1001-1017.

Devine, F., Savage, M., Scott, J., \& Crompton, R. (2005). Rethinking class. Palgrave.

Frank, S., \& Weck, S. (2018). Being good parents or being good citizens: Dilemmas and contradictions of urban families in middle-class enclaves and mixed neighbourhoods in Germany. International Journal of Urban and Regional Research, 4(1), 20-35.

Goodsell, T. L. (2013). Familification: Family, neighborhood change, and housing policy. Housing Studies, 28(6), 845-868.

Hanhörster, H., \& Weck, S. (2020). Middle-class family encounters and the role of micro-publics for crosssocial interaction. In S. Musterd (Ed.), Handbook of urban segregation (pp. 254-269). Edward Elgar Publishing.

Hoekstra, M. S., \& Pinkster, F. M. (2019). “We want to be there for everyone": Imagined spaces of encounter and the politics of place in a super-diverse neighbourhood. Social \& Cultural Geography, 20(2), 222-241.

Jackson, E., \& Butler, T. (2015). Revisiting "social tectonics": The middle classes and social mix in gentrifying neighbourhoods. Urban Studies, 52(13), 2349-2365.

Jennings, J. L. (2010). School choice or schools' choice? Managing in an era of accountability. Sociology of Education, 83(3), 227-247.
Karsten, L. (2014). From yuppies to yupps: Family gentrifiers consuming spaces and re-inventing cities. Tijdschrift Voor Economische En Sociale Geografie, 105(2), 175-188.

Landeshauptstadt Düsseldorf. (2020). Kommunale Sozialberichterstattung: Soziale Lage Düsseldorf, Monitoringbericht 2014-2019 [Local government social reporting: The social situation in Düsseldorf 2014-2019]. Amt für Statistik und Wahlen.

Landeshauptstadt Hannover. (2018). Statistische Profile der Stadtteile und Stadtbezirke 2018 [Statistical profiles of city districts 2018]. Fachbereich Personal und Organisation.

Landeshauptstadt Hannover. (2021). Strukturdaten der Stadtteile und Stadtbezirke 2019 [Structual data of city districts 2019]. Fachbereich Personal und Organisation.

Lawson, V., Elwood, S., Canevaro, S., \& Viotti, N. (2016). "The poor are us": Middle-class poverty politics in Buenos Aires and Seattle. Environment and Planning A, 47(9), 1873-1891.

Lees, L., Shin, H. B., \& López-Morales, E. (2016). Planetary gentrification. Urban futures. Polity Press.

Ley, D. (1996). The new middle class and the remaking of the central city. Oxford geographical and environmental studies. Oxford University Press.

Noreisch, K. (2007). Choice as rule, exception and coincidence: Parents' understandings of catchment areas in Berlin. Urban Studies, 44(7), 1307-1328.

Pinkster, F. M. (2013). "I just live here": Everyday practices of disaffiliation of middle-class households in disadvantaged neighbourhoods. Urban Studies, 51(4), 810-826.

Pinkster, F. M. (2016). Narratives of neighbourhood change and loss of belonging in an urban garden village. Social \& Cultural Geography, 17(7), 871-891.

Ramos Lobato, I. (2017). "I do not want to poach pupils from other schools": German primary schools and their role in educational choice processes. Belgeo, 2017(2/3). https://journals.openedition.org/belgeo/ 19131

Ramos Lobato, I., \& Groos, T. (2019). Choice as a duty? The abolition of primary school catchment areas in North Rhine-Westphalia/Germany and its impact on parent choice strategies. Urban Studies, 56(15), 3274-3291.

Raveaud, M., \& van Zanten, A. (2007). Choosing the local school: Middle class parents' values and social and ethnic mix in London and Paris. Journal of Education Policy, 22(1), 107-124.

Reay, D., Hollingworth, S., Williams, K., Crozier, G., Jamieson, F., James, D., \& Beedell, P. (2007). A darker shade of pale? Whiteness, the middle classes and multi-ethnic inner city schooling. Sociology, 41, 1041-1060.

Valentine, G. (2008). Living with difference: Reflections on geographies of encounter. Progress in Human Geography, 32(3), 323-337. 
van Eijk, G. (2010). Does living in a poor neighbourhood result in network poverty? A study on local networks, locality-based relationships and neighbourhood settings. Journal of Housing and the Built Environment, 25(4), 467-480.

van Zanten, A. (2013). A good match: Appraising worth and estimating quality in school choice. In J. Beckert \& C. Musselin (Eds.), Constructing quality: The classification of goods in markets (pp. 77-99). Oxford Scholarship Online.

Vincent, C., Ball, S. J., \& Kemp, S. (2004). The social geography of childcare: Making up a middle-class child. British Journal of Sociology of Education, 25(2), 229-244.

Watt, P. (2009). Living in an oasis: Middle-class disaffiliation and selective belonging in an English suburb. Environment and Planning A, 41(12), 2874-2892.

Wessendorf, S. (2014). Commonplace diversity: Social relations in a super-diverse context. Palgrave Macmillan.

Wilson, H. F. (2014). Multicultural learning: Parent encounters with difference in a Birmingham primary school. Transactions of the Institute of British Geographers, 39(1), 102-114.

Wimmer, A. (2008). Ethnische Grenzziehung in der Immigrationsgesellschaft. Jenseits des Herder'schen Commonsense [Ethnic boundary making in immigration societies: Beyond Herder's theory of common sense]. Kölner Zeitschrift für Soziologie und Sozialpsychologie, 48, 57-80.

Zimmer-Hegmann, R. (2020). Düsseldorf: Zwischen Dorf und Metropole [Düsseldorf: A village or a metropolis?]. In D. Rink \& B. Egner (Eds.), Lokale Wohnungspolitik: Beispiele aus deutschen Städten [Local housing policy: Examples of German Cities] (pp. 139-158). Nomos Verlag.

\section{About the Authors}

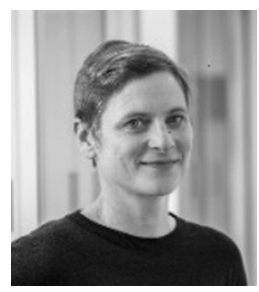

Heike Hanhörster is senior researcher at the ILS-Research Institute for Regional and Urban Development in Dortmund, Germany. Her research interest covers place-based processes of social inclusion and exclusion, and people's encounters with difference. Her recent research includes social networks of households in low-income neighbourhoods, institutional discrimination, and exclusionary processes on the housing market, middle-class disaffiliation strategies, as well as neighbourhood choice and affiliations of Turkish middle-class households.

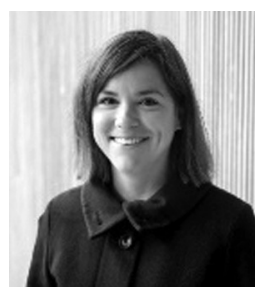

Isabel Ramos Lobato works as a post-doctoral researcher at the Helsinki Institute of Urban and Regional Studies, University of Helsinki, and is part of the Geographies of Education and Divided Cities (GED) research group. Her research interests are broadly rooted in urban and social geography, with a focus on social inclusion and exclusion in the fields of education and housing. In her PhD, she examined parents' choice of primary schools and its impact on school segregation in Germany.

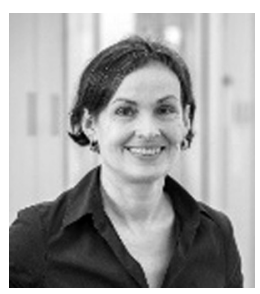

Sabine Weck heads the Urban Social Space Research Group at the ILS-Research Institute for Regional and Urban Development (ILS) in Dortmund, Germany. She focuses on themes of socio-spatial inequalities, social cohesion, and spatial justice. She has published articles together with colleagues on innercity neighbourhoods and middle-class disaffiliation strategies, poverty and social exclusion, as well as place-based development strategies in disadvantaged areas. 